2. Jansen, M.A., Gaba, V., Greenberg, B.M. (1998). Higher plants and UV-B radiation: balancing damage, repair and acclimation. Trends in plant science, 3(4), 131-135.

3. Fina, J., Casadevall, R., AbdElgawad, H., Prinsen, E., Markakis, M. N., Beemster, G. T., \& Casati, P. (2017). UV-B inhibits leaf growth through changes in growth regulating factors and gibberellin levels. Plant physiology, 174(2), 1110-1126.

4. Brown, B.A., Cloix, C., Jiang, G.H., Kaiserli, E., Herzyk, P., Kliebenstein, D.J., Jenkins, G.I. (2005). A UV-B-specific signaling component orchestrates plant UV protection. Proceedings of the National Academy of Sciences, 102(50), 1822518230.

5. Robson, T.M., Klem, K., Urban, O., \& Jansen, M.A. (2015). Re-interpreting plant morphological responses to UV-B radiation. Plant, cell \& environment, 38(5), 856-866.

6. Rizzini, L., Favory, J. J., Cloix, C., Faggionato, D., O’Hara, A., Kaiserli, E., ... \& Ulm, R. (2011). Perception of UV-B by the Arabidopsis UVR8 protein. Science, 332(6025), 103-106.

7. González Besteiro, M. A., Bartels, S., Albert, A., \& Ulm, R. (2011). Arabidopsis MAP kinase phosphatase 1 and its target MAP kinases 3 and 6 antagonistically determine UV-B stress tolerance, independent of the UVR8 photoreceptor pathway. The Plant Journal, 68(4), 727-737.

8. Hideg, É., Jansen, M. A., \& Strid, Å. (2013). UV-B exposure, ROS, and stress: inseparable companions or loosely linked associates?. Trends in plant science, 18(2), $107-115$.

9. Heuberger, H., Praeger, U., Georgi, M., Schirrmacher, G., Grasmann, J., \& Schnitzler, W.H. (2004, March). Precision stressing by UV-B radiation to improve quality of spinach under protected cultivation. In VII International Symposium on Protected Cultivation in Mild Winter Climates: Production, Pest Management and Global Competition 659 (pp. 201-206).

10. Tenhaken, R. (2015). Cell wall remodeling under abiotic stress. Frontiers in plant science, 5,771 .

DOI 10.18699/GPB2020-16

\title{
Реконструкция регуляторных генных сетей ответа на солевой стресс Arabidopsis thaliana и Zea mays
}

Бобровских А.В. ${ }^{l}$, м.н.с.; Ермаков А.А. ${ }^{l *}$, м.н.с.; Зубаирова У.С. ${ }^{1}$, к.б.н., н.с.; Константинов Д.К. ${ }^{\text {, }, ~ м . н . с . ; ~ Л е в и н а ~ А . Б . ~}{ }^{2}$, студентка; Дорошков А.В. ${ }^{l}$, к.б.н., H.c.

${ }^{1}$ ИЦиГ СО РАН, Новосибирск, Россия;

${ }^{2}$ НГУ, Новосибирск, Россия;

*e-mail:ermakov@bionet.nsc.ru

Засоление является одним из важнейших абиотических факторов, ограничивающих зоны возделывания сельскохозяйственных культур. Ответ 
растений на засоленость комплексный и его генетическая компонента на данный момент изучена недостаточно. В настоящей работе проведена интеграчия данных, реконструкиия и сопоставление генных сетей между перспективными модельными и селекционно ценными видами растений с иелью выявления генов-кандидатов для селекции и интрогрессии от диких сородичей.

Ключевые слова: абиотический стресс, стрессоустойчивость, засоление, сельское хозяйство, кукуруза, арабидопсис.

\section{Reconstruction of regulatory gene networks of response to salt stress Arabidopsis thaliana and Zea mays}

Bobrovskih A.V., Ermakov A.A., Zubairova U.S., Konstantinov D.K., Levina A.B., Doroshkov A.V.

ICG SB RAS, Novosibirsk, Russia;

Novosibirsk State University, Novosibirsk, Russia.

*e-mail:ermakov@bionet.nsc.ru

Salinization is one of the most important abiotic factors limiting crop cultivation zones. The response of plants to salinity is complex and its genetic component has not been studied sufficiently. In the present work, data integration, reconstruction and comparison of gene networks between promising model and breeding valuable plant species was carried out in order to identify candidate genes for selection and introgression from wild relatives.

Key words: abiotic stress, stress resistance, salinization, agriculture, maize, arabidopsis.

Перед наукой стоят задачи, как увеличения продуктивности культурных растений, так и расширения засеваемых площадей. Этому препятствуют различные факторы, в том числе глобальное изменение климата, возрастающее техногенное давление на культурные растения и необдуманное использование удобрений. Засоление является одним из важнейших абиотических факторов, ограничивающих зоны возделывания сельскохозяйственных культур. Так, известно, что засоленно-солонцовые почвы в Новосибирской области занимают до $50 \%$ от общей площади сельскохозяйственных угодий [1]. В мировых масштабах естественное засоление почв также является общепризнанной проблемой, которая оказывает негативное влияние на продуктивность культурных растений [2], препятствует освоению новых посевных земель и делает непригодными имеющиеся. Техногенное засоление почв представляет собой не меньшую проблему [3]. Решением данной проблемы является рекультивация земель, подвергшихся засолению, и выведение новых форм культурных растений, устойчивых к засолению.

В процессе доместикации растений, как правило, использовали ограниченное число индивидуумов видов-предшественников, а контролируемые 
в процессе отбора признаки обычно были связаны с общей урожайностью, технологическими и вкусовыми качествами $[4,5]$. Результатом такого отбора стало снижение общего генетического разнообразия культурных растений [6-8]. Отбор на максимизацию урожайности в условиях определенной климатической зоны и географического местоположения привел к тому, что полученные сорта часто имеют невысокую устойчивость к любым отклонениям условий окружающей среды от оптимальных, что заметно снижает их продуктивность в стрессовых условиях [9]. Поэтому, перед современными селекционерами и биотехнологами остро стоит задача расширения генофонда, для чего активно используется гибридизация, в т.ч. отдаленная, как способ получения нового селекционного материала.

Известно, что кукуруза (Zea mays L.) слабо устойчива к засолению, тогда как у многих диких сородичей культурных злаков установлена повышенная устойчивость к засоленности. Современные методы селекции с использованием биотехнологических подходов позволяют эффективно переносить ценные хозяйственные признаки из имеющегося генетического материала в культивируемые сорта культурных растений. Таким образом, основной задачей, стоящей перед исследователями сегодня, является поиск генов, реализующих заданные ценные признаки, и получение нового генетического материала для селекционной работы, в т.ч. и среди диких родственных видов, допускающих гибридизацию.

В настоящее время известно, что реакции ответа на солевой стресс можно разделить на специфические и неспецифические. Специфические реакции заключаются в индукции синтеза стрессовых белков, тогда как неспецифические компоненты системы ответа на стресс связаны, прежде всего, с антиоксидантной системой. Физиология специфических реакций достаточно подробно изучена на модельном организме арабидопсисе: поступление ионов $\mathrm{Na}+$ в клетку активирует каскады процессов изменяющие в итоге ионный, водный и гормональный гомеостаз всего растения [10]. Абиотические виды стресса приводят к увеличению концентрации радикалов кислорода, в связи с чем антиоксидантная система защиты, активирующаяся в ответ на широкий спектр стрессов, привлекла к себе пристальное внимание еще два десятилетия назад $[11,12]$. Было выявлено, что компоненты антиоксидантной системы включают серии генов с идентичной молекулярной функцией, но различной клеточной локализацией [13].

Применение системно-биологических подходов для изучения генетических механизмов адаптации с большим числом взаимосвязей представляется наиболее эффективным решением задачи на настоящее время, однако их применение для улучшения культурных растений впервые упомянуто относительно недавно [14]. Сейчас относительно полное понимание функционирование механизма ответа на солевой стресс существует только на примере модельного объекта Arabidopsis thaliana, тогда как для злаков и других 
растений существуют лишь отдельные факты о некоторых генах, которые повышают устойчивость к солевому стрессу. В связи с этим существует необходимость применения подходов системной биологии для интеграции имеющихся разнородных данных для ряда видов, с целью установления механизмов защиты от солевого стресса.

Целью настоящего исследования является интеграция транскриптомных данных по арабидопсису и злакам (Oryza sativa, Zea mays) для описания общих и видоспецифичных компонентов системы ответа на солевой стресс кукурузы Zea mays, как слабоустойчивого к засолению представителя злаковых. Было проведено межвидовое сравнение реконструированных генных сетей, обогащенных транскриптомными данными. С одной стороны, удобной моделью для построения генных сетей является база знаний Arabidopsis thaliana. C другой стороны, выявление ассоциированных генов с солевым стрессом у злаков в ходе транскриптомного анализа позволит также детектировать соответствующих ортологов в геноме арабидопсиса. Следовательно, такой интегративный подход позволит описать наиболее полно генную сеть ответа соответствующих злаков.

В ходе работы был проведен анализ транскриптомных данных для выявления генов-кандидатов у Arabidopsis thaliana. Было выявлено более 3000 дифференциально экспрессирующихся в условиях солевого стресса генов. Была проведена приоритизация и ранжирование генов в данной выборке тремя различными способами, учитывая как достоверность, так и уровень изменения экспрессии гена. В результате было отобрано 1099 генов-кандидатов.

На основании выявленных генов-кандидатов была реконструирована генная сеть с использованием базы данных String (http://string-db.org/, Szklarczyk D. et al., 2016) и списка уже известных генов солевого ответа. Полученная обогащенная генная сеть включает в себя 99 генов, ассоциация которых с ответом на солевой стресс была известна ранее и 268 связанных с ними генов-кандидатов, и регуляцией метаболических процессов (ферменты, транскрипционные факторы, белки-транспортеры, гены фотосистем, антиоксидантные гены).

При помощи подходов сравнительной геномики, мета анализа транскриптомных данных и подходов молекулярной филогении нами были сопоставлены реконструированные и расширенные сети ответа на солевой стресс между A. thaliana, Zea mays, Oryza sativa, Hordeum vulgare u Triticum aestivum.

В результате было выявлен ряд новых генов ответа на солевой стресс, например, гены-регуляторы биосинтеза аминокислот, компоненты рибонуклеопротеидных комплексов, транспортеры азота и калия, белки индуцируемые абсцизовой кислотой, ауксином и этиленом, что свидетельствует в пользу комплексности найденного ответа, а также ряд ферментов редуктаз и 
оксидаз, меняющих окислительно-восстановительный баланс клетки.

Благодарности: Исследование выполнено при финансовой поддержке РФФИ и Правительства Новосибирской области в рамках научного проекта № 19-416-543006.

\section{Список литературы}

1. Панкова Е.И., Конюшкова М.В., Горохова И.Н. О проблеме оценки засоленности почв и методике крупномасштабного цифрового картирования засоленных почв (2017). Экосистемы: экология и динамика.

2. Food and Agriculture: Key to Achieving the 2030, Agenda for Sustainable Development. Job No. I5499, Food and Agriculture Organization of the United Nations,

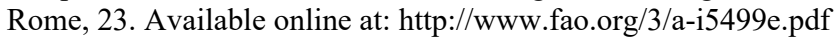

3. Артамонова В.С., Дитц Л.Ю., Елизарова Т.Н., Лютых И.В. (2010). Техногенное засоление почв и их микробиологическая характеристика. Сибирский Экологический Журнал, 3 (2010) 461-470.

4. Hua, L., Wang, D.R., Tan, L.B., Fu, Y.C., Liu, F.X., Xiao, L.T., ... Sun, C.Q. (2015). LABA1, a domestication gene associated with long, barbed awns in wild rice. The Plant Cell, 27, 1875-1888.

5. Konishi, S., Lin, S. Y., Ebana, K., Fukuta, Y., Izawa, T., Sasaki, T. and Yano, M. (2006). A SNP caused the loss of seed shattering during rice domestication. Science, 312, $1392-1396$.

6. Buckler, E.S., Thornsberry, J.M. and Kresovich, S. (2001). Molecular diversity, structure and domestication of grasses. Genetical Research, 77, 213-218.

7. Miller, A.J. and Gross, B.L. (2011). From forest to field: Perennial fruit crop domestication. American Journal of Botany, 98, 1389-1414.

8. Meyer, R.S., DuVal, A.E. and Jensen, H.R. (2012). Patterns and processes in crop domestication: An historical review and quantitative analysis of 203 global food crops. New Phytologist, 196, 29-48.

9. Ramírez, J.I.S., \& Maiti, R. (2016). Research Trends in Abiotic Stress Resistance of Crops. In BioresourceandStressManagement (pp. 131-163). SpringerSingapore.

10. Deinlein, Ulrich et al. 2014. "Plant Salt-Tolerance Mechanisms." Trends in Plant Science 19(6): 371-79.

11. Cazalé, Anne Claire et al. 1999. "MAP Kinase Activation by Hypoosmotic Stress of Tobacco Cell Suspensions: Towards the Oxidative Burst Response?" Plant Journal 19(3): 297-307.;

12. Orozco-Cardenas, Martha, and Clarence A Ryan. 1999. "Hydrogen Peroxide Is Generated Systemically in Plant Leaves by Wounding and Systemin via the Octadecanoid Pathway." Plant Biology 96 (May): 6553-57.

13. Pang CH, Wang BS (2010) Role of ascorbate peroxidase and glutathione reductase in ascorbate-glutathione cycle and stress tolerance in plants.

14. Jogaiah, S., Govind, S. R., \& Tran, L. S. P. (2013). Systems biology-based approaches toward understanding drought tolerance in food crops. Criticalreviewsinbiotechnology, 33 (1), 23-39. 